\title{
Treatment of supracondylar fracture of the humerus (type IIB and III) in children: A prospective randomized controlled trial comparing two methods
}

\author{
Pandey $\mathrm{S}^{1}$, Shrestha $\mathrm{D}^{2}$, Gorg $\mathbf{M}^{3}$, Singh $\mathbf{G K}^{4}$, Singh $\mathbf{M P}^{5}$ \\ ${ }^{1}$ Registrar, Department of Orthopaedic, BP. Memorial Cancer Hospital, Bharatpur, Nepal, ${ }^{2}$ Assistant Professor, \\ Kathmandu University School of Medical Sciences, Dhulikhel, Nepal, ${ }^{3}$ Former Associate Professor, ${ }^{5}$ Professor, \\ Department of Orthopaedics, B P. Koirala Institute of Health Sciences, Dharan, Nepal, ${ }^{4}$ Department of Orthopaedics, \\ King George Medical College, Lucknow, India.
}

\begin{abstract}
Background: Consensus on method of treatment of displaced supracondylar fracture of the humerus in children is still lacking. Purpose of this prospective randomized controlled study is to compare closed reduction and long arm slab application with closed reduction and percutaneous crossed Kirschner wires fixation.

Materials and methods: Children of age less than 12 years presented in B.P. Koirala institute of health sciences, Dharan in one year were randomly allocated to group A and group B consisting 30 patients in each group. Closed reduction and long arm posterior slab was applied in group A and in group B, closed reduction was followed by crossed Kirschner wires fixation. Clinical and radiological evaluation of reduction was performed immediately after procedure and at the end of first week, third week, third month and sixth month.

Results: The groups were matched for pre fracture characteristics and post reduction evaluation. The mean follow up period in group A was 6.9 months and in group B was 7.1 months. Closed reduction failed in two patients at the first attempt and one patient failed to retain reduction at first week in group A. 11 patients (5 in group A and 6 in group B) were lost to follow up. Range of movement, valgus, varus and carrying angle of elbow in two groups were not significantly different. The mean difference of carrying angle of affected elbow as compare to normal elbow was significant in group A $(\mathrm{p} \leq 0.05)$. Flynn's overall rating showed $32 \%$ excellent, $36 \%$ good, $18 \%$ fair and $14 \%$ poor result in patents treated with long arm slab as compared to 58\% excellent, $29 \%$ good, $13 \%$ fair and no poor results in patients with crossed Kirschner wires fixation.

Conclusion: The outcome of displaced extension type supracondylar fracture of the humerus in children, managed with closed reduction and slab application are comparable with closed reduction and crossed Kirschner wire fixation in terms of range of motion but is inferior in restoration of carrying angle. Good to excellent cosmetic and functional results are higher with crossed percutaneous Kirschner wires fixation than with slab immobilization.
\end{abstract}

Key words: closed reduction; percutaneous fixation; supracondylar fracture

upracondylar fracture account for $50-70 \%$ of all
elbow fracture in children between the ages of
3-10 years and more than $95 \%$ supracondylar fractures
are extension type ${ }^{1,2}$. Current method of treatment
of supracondylar fracture is based upon Gartland
classification ${ }^{3}$. Primary aims of treatment of displaced
supracondylar fracture of humerus (Gartland type IIB
and III) in children to achieve stable reduction, to
prevent nerve injury and vascular compromise leading
to compartment syndrome and in long term to reduce
cubitus varus deformity. Many methods of treatment
have been discussed for displaced supracondylar
fracture such as close reduction and long arm cast or
slab application, Dunlop's skin traction, olecranon skeletal traction with screw or transverse Kirschner wire, closed reduction and percutaneous crossed Kirschner wires fixation or lateral two parallel wires, Dorgan's percutaneous lateral cross-wiring, open reduction and internal fixation with crossed Kirschner wires or transarticular fixation ${ }^{1,4,5,6,7,8,9,10,11,12}$. But the results of various methods of treatment have not been supported by randomised controlled trials yet.

\footnotetext{
Correspondence

Dr. Dipak Shrestha

Assistant Professor

Kathmandu University School of Medical Sciences

Dhulikhel, Nepal

E-mail: dsmsortho@yahoo.com
} 
We report the result of the prospective randomised controlled trial comparing closed reduction and long arm splintage with closed reduction and percutaneous crossed Kirschner wires fixation for Gartland type IIB and III supracondylar fracture of humerus in children

\section{Materials and methods}

Patients below 12 years of age with closed extension type Gartland type IIB and III supracondylar fracture of humerus who presented within 7 days of injury in B. P Koirala Institute of Health sciences, Dharan in between $1^{\text {st }}$ Jan 2004 to $31^{\text {st }}$ Dec 2004 were randomised into two groups according to treatment method applied, consisting of 30 patients in each group. (Fig 1)

Patients in group A were managed with closed reduction under general anaesthesia or regional block with standard technique and splinted with long arm plaster of Paris slab with elbow in hyperflexion and forearm in supination for posterio-lateral displaced or in pronation for posterio-medial displaced fracture. ${ }^{1}$ Reduction was confirmed by immediate post reduction radiographs in two planes. Anterioposterior view was used to evaluate translation in coronal plane and lateral view for shaft condylar angle and rotation in horizontal plane ${ }^{4}$. (Fig 2a,2b)

In group $\mathrm{B}$, under general anaesthesia, closed reduction and crossed Kirschner wires (2mm) fixation performed under $\mathrm{C}$ arm control. For posteriolaterally displaced fracture, lateral pin was passed first through lateral epicondyle and for posteriomedially displaced fracture medial pin was passed first through medial epicondyle. While passing medial pin, ulnar nerve was rolled back with the opposite thumb to prevent iatrogenic ulnar nerve injury. Wires were bent and left outside skin. Long arm plaster of Paris slab applied with elbow in 90 degree flexion and forearm in supination. Immediate post operative anterior-posterior and lateral radiographs were evaluated for adequacy of reduction. (Fig 3a,3b)

All patients were discharged within 24 hours of procedure. Patients in group B were advised to take antibiotic for three days and Kirschner wires were removed after three 3 weeks. Active range of motion of elbow was started after 3 weeks in both groups. Clinical and radiographic assessments of reduction was performed immediately after 1 week , 3 weeks, 3 months and 6 months follow up in both groups by neutral observer (Fig 2c,3c). Range of movements and carrying angle of affected and normal elbow were measured (Fig $4 \mathrm{a}, 4 \mathrm{~b})$ and evaluated on the basis of Flynn's criteria and overall rating was assessed by modified Flynn classification $^{9,13}$. (Table 1)

Eleven patients were lost to follow up, five in group A and six in group B. In group A, initial attempts of closed reduction failed in two and one patient failed to retain reduction on first week of follow up. These three cases were managed with the open reduction and Kirschner wire fixation on the principle of intention to treat analysis and not included in the final analysis in any of two groups. One case in group B had ipsilateral fracture of distal fourth both bone which was reduced and fixed with crossed Kirschner wires under $\mathrm{C}$ arm control.

\section{Statistical analysis}

Success of the randomisation was tested between two groups. Magnitude of difference was measured as difference between means in both groups by Epi-info 2000 software. Significance of difference was measured by determining $\mathrm{p}$ value and value below 0.05 was considered significant.

\section{Results}

The two groups were comparable in pre fracture characteristics, fracture pattern and post reduction radiographic measurements showing success of randomization. (Table 2)

The mean follow up period in group A was 6.9 months and in group B was 7.1 months. Evaluation at final follow up revealed no statistically significant differences in mean varus, valgus and mean carrying angle between two groups. (Table 3) Mean flexion and extension of elbow, external rotation of shoulder and supination and pronation of forearm in both groups were not statistically significant. Mean values of flexion, extension and carrying angle of the affected and normal elbow were also calculated in both groups (Table 4). There was decrease in mean flexion and increase in extension of injured elbow in both groups as compared to normal side. Though it was small in amount, the loss of carrying angle between normal and the affected side and in between 2 groups was statistically significant.

Analysis of result on the basis of Flynn's criteria in both groups revealed no statistically significant difference (Table 5) ${ }^{9}$. Good to excellent result were $87 \%$ and $95 \%$ in cosmetic factor and in functional factor respectively in group B as compare to $68 \%$ and $91 \%$ in group A. Worst scenario case analysis considering all lost to follow up cases and failed reduction cases were against the hypothesis found no statistically significant differences in Flynn's criteria. (Table 6)

One patient in group A had radial nerve palsy at the time of presentation which recovered completely in 3 months follow up with conservative treatment. In group $\mathrm{B}$, one case developed ulnar nerve palsy after fixation for which medial pin was removed immediately and supplemented with another lateral Kirschner wire. Nerve palsy recovered in 6 weeks with conservative treatments. Pin tract infections and Volkmann ischaemia were not found in the present study. 
Table 1: Flynn's criteria and overall rating

\begin{tabular}{|c|c|c|c|}
\hline & \multicolumn{3}{|l|}{ Flynn's criteria } \\
\hline & $\begin{array}{l}\text { Cosmetic factor } \\
\text { Carrying angle loss } \\
\text { (degrees) }\end{array}$ & $\begin{array}{l}\text { Functional factor } \\
\text { Movement loss } \\
\text { (degrees) }\end{array}$ & Overall rating \\
\hline Excellent & 0 to 5 & 0 to 5 & \multirow{4}{*}{$\begin{array}{l}\text { The lower of the two ratings } \\
\text { and the elbow with a varus } \\
\text { deformity is automatically } \\
\text { graded as poor }\end{array}$} \\
\hline Good & 5 to 10 & 5 to 10 & \\
\hline Fair & 10 to 15 & 10 to 15 & \\
\hline Poor & $>15$ & $>15$ & \\
\hline
\end{tabular}

Table 2: Pre and post-reduction variables in slab (Group A) and pinning (Group B) method of treatment

\begin{tabular}{|c|c|c|c|}
\hline Variables & Group A $(n=30)$ & Group B $(n=30)$ & p value \\
\hline Age $(\mathrm{yrs}) *$ & $7.6 \pm 3.4$ & $7.8 \pm 2.2$ & 0.923 \\
\hline \multicolumn{3}{|l|}{ Gender } & \multirow[b]{2}{*}{0.281} \\
\hline $\begin{array}{l}\text { Male } \\
\text { Female }\end{array}$ & $\begin{array}{c}23 \\
7\end{array}$ & $\begin{array}{l}18 \\
12\end{array}$ & \\
\hline \multicolumn{3}{|l|}{ Mode of injury } & \multirow[b]{2}{*}{0.1264} \\
\hline $\begin{array}{l}\text { Play ground injury } \\
\text { Fall injury } \\
\text { Road traffic accident } \\
\text { Others }\end{array}$ & $\begin{array}{c}15 \\
10 \\
2 \\
3 \\
\end{array}$ & $\begin{array}{c}20 \\
10 \\
- \\
- \\
\end{array}$ & \\
\hline \multicolumn{3}{|l|}{ Affected side } & \multirow[b]{2}{*}{0.794} \\
\hline $\begin{array}{l}\text { Right } \\
\text { Left }\end{array}$ & $\begin{array}{l}13 \\
17\end{array}$ & $\begin{array}{l}11 \\
19\end{array}$ & \\
\hline \multicolumn{3}{|l|}{ Primary splintage } & \multirow[b]{2}{*}{0.7921} \\
\hline $\begin{array}{l}\text { Yes } \\
\text { No }\end{array}$ & $\begin{array}{l}17 \\
13 \\
\end{array}$ & $\begin{array}{l}19 \\
11 \\
\end{array}$ & \\
\hline \multicolumn{3}{|l|}{ Displacement } & \multirow[b]{2}{*}{0.3329} \\
\hline $\begin{array}{l}\text { Posteriomedial } \\
\text { Posteriolateral }\end{array}$ & $\begin{array}{c}22 \\
8 \\
\end{array}$ & $\begin{array}{c}26 \\
4\end{array}$ & \\
\hline Injury- Hospital duration (hrs) ${ }^{*}$ & $15.6 \pm 12.1$ & $20.1 \pm 5.7$ & 0.2235 \\
\hline \multicolumn{3}{|l|}{ Anaesthesia used } & \multirow[b]{2}{*}{0.413} \\
\hline $\begin{array}{l}\text { General } \\
\text { Regional }\end{array}$ & $\begin{array}{l}18 \\
12 \\
\end{array}$ & $\begin{array}{c}22 \\
8 \\
\end{array}$ & \\
\hline Hospital- treatment duration (hrs) $*$ & $5.5 \pm 2.6$ & $6 \pm 2.2$ & 0.177 \\
\hline \multicolumn{4}{|l|}{ Post reduction evaluation } \\
\hline \multicolumn{3}{|l|}{ Posterior Shift } & \multirow[b]{2}{*}{1.000} \\
\hline $\begin{array}{l}\text { Present } \\
\text { Absent }\end{array}$ & $\begin{array}{c}2 \\
28 \\
\end{array}$ & $\begin{array}{c}1 \\
29 \\
\end{array}$ & \\
\hline \multicolumn{3}{|l|}{ Medial-Lateral Tilt } & \multirow[b]{2}{*}{1.000} \\
\hline $\begin{array}{l}\text { Present } \\
\text { Absent }\end{array}$ & $\begin{array}{c}0 \\
30\end{array}$ & $\begin{array}{c}0 \\
30\end{array}$ & \\
\hline \multicolumn{3}{|l|}{ Medial-Lateral Shift } & \multirow[b]{2}{*}{0.666} \\
\hline $\begin{array}{l}\text { Present } \\
\text { Absent }\end{array}$ & $\begin{array}{c}2 \\
28\end{array}$ & $\begin{array}{c}4 \\
26\end{array}$ & \\
\hline Shaft-Condylar angle * & $34.8 \pm 5.1^{\circ}$ & $35.8 \pm 5.5^{\circ}$ & 0.4871 \\
\hline
\end{tabular}

* The values are given as mean \pm standard deviation 
Table 3: Outcomes in slab (Group A) and pinning (Group B) method of treatment

\begin{tabular}{|l|c|c|c|}
\hline \multicolumn{1}{|c|}{ Variables } & $\begin{array}{l}\text { Group A( n=22) } \\
\text { mean } \pm \text { SD }\end{array}$ & $\begin{array}{l}\text { Group B( }=\mathbf{2 4 )} \\
\text { mean } \pm \text { SD }\end{array}$ & p value \\
\hline Loss of elbow flexion & $6.9 \pm 5.4^{\circ}$ & $5.5 \pm 3.7^{\circ}$ & 0.321 \\
\hline Elbow extension ${ }^{\dagger}$ & $-1.5 \pm 3^{\circ}$ & $-1.7 \pm 2.8^{\circ}$ & 0.7381 \\
\hline Shoulder external rotation & $65.9 \pm 5^{\circ}$ & $64.1 \pm 7.1^{\circ}$ & 0.3496 \\
\hline Forearm supination & $85.6 \pm 4.4^{\circ}$ & $84.7 \pm 4^{\circ}$ & 0.4800 \\
\hline Forearm pronation & $78.7 \pm 17^{\circ}$ & $83.3 \pm 4.8^{\circ}$ & 0.2110 \\
\hline Valgus angle & $3.8 \pm 3.7^{\circ}$ & $5.9 \pm 4^{\circ}$ & 0.0772 \\
\hline Varus angle & $1.5 \pm 2.7^{\circ}$ & $0.5 \pm 1.3^{\circ}$ & 0.1140 \\
\hline Carrying angle & $2.2 \pm 5.8^{\circ}$ & $5.3 \pm 5^{\circ}$ & 0.0602 \\
\hline
\end{tabular}

$\dagger$ Negative value for extension indicates recurvatum

Table 4: Comparison of outcomes of affected elbow with normal side in slab (Group A) and pinning (Group B) method of treatment

\begin{tabular}{|l|c|c|c|c|c|c|c|}
\hline \multirow{2}{*}{ Variables } & \multicolumn{2}{|c|}{$\begin{array}{c}\text { Group A( } \\
\text { mean } \pm \text { SD }\end{array}$} & \multirow{2}{*}{$\begin{array}{c}\text { Mean of } \\
\text { diff. }\end{array}$} & \multicolumn{2}{|c|}{$\begin{array}{c}\text { Group B( n=24) } \\
\text { mean } \pm \text { SD }\end{array}$} & \multirow{2}{*}{$\begin{array}{c}\text { Mean of } \\
\text { diff. }\end{array}$} & \multirow{2}{*}{ p value } \\
& \multicolumn{2}{|c|}{ Normal Affected } & & Normal Affected & & \\
\hline Carrying angle & $11.1 \pm 2.1^{\circ}$ & $2.2 \pm 5.8^{\circ}$ & $8.9 \pm 5.5^{\circ}$ & $11 \pm 2.6^{\circ}$ & $5.3 \pm 5^{\circ}$ & $5.7 \pm 4.4^{\circ}$ & 0.0422 \\
\hline Flexion & $137 \pm 5.4^{\circ}$ & $131 \pm 7.4^{\circ}$ & $5.9 \pm 5.9^{\circ}$ & $136 \pm 4.5^{\circ}$ & $132 \pm 5.4^{\circ}$ & $4.1 \pm 4^{\circ}$ & 0.3628 \\
\hline Extension $^{\dagger}$ & $-4 \pm 4^{\circ}$ & $-1.5 \pm 3^{\circ}$ & $-2.1 \pm 3.6^{\circ}$ & $-3.7 \pm 3.4^{\circ}$ & $-1.7 \pm 2.8^{\circ}$ & $-2 \pm 2.6^{\circ}$ & 0.7977 \\
\hline
\end{tabular}

${ }^{\dagger}$ Negative value for extension indicates recurvatum

Table 5: Results Flynn's criteria and overall rating in slab (Group A) and pinning (Group B) method of treatment

\begin{tabular}{|l|c|c|c|c|c|c|}
\hline \multirow{2}{*}{ Variables } & \multicolumn{3}{|c|}{ Group A (n=22) } & \multicolumn{3}{c|}{ Group B( n=24) } \\
\cline { 2 - 7 } & $\begin{array}{c}\text { Functional } \\
\text { factor }\end{array}$ & $\begin{array}{c}\text { Cosmetic } \\
\text { factor }\end{array}$ & Overall result & $\begin{array}{c}\text { Functional } \\
\text { factor }\end{array}$ & $\begin{array}{c}\text { Cosmetic } \\
\text { factor }\end{array}$ & Overall result \\
\hline Excellent & 10 & 7 & 7 & 18 & 14 & 14 \\
\hline Good & 10 & 8 & 8 & 5 & 7 & 7 \\
\hline Fair & 1 & 4 & 4 & 1 & 3 & 3 \\
\hline Poor & 1 & 3 & 3 & - & - & - \\
\hline
\end{tabular}

Chi- square $\mathrm{p}$ value for functional factor is 0.1812

Chi- square $\mathrm{p}$ value for cosmetic factor is 0.1407 
Table 6: Worst case scenario analysis of Flynn's criteria in slab (Group A) and pinning (Group B) method of treatment

\begin{tabular}{|l|c|c|c|c|c|c|}
\hline \multirow{2}{*}{ Variables } & \multicolumn{3}{|c|}{ Group A (n=30) } & \multicolumn{3}{c|}{ Group B (n=30) } \\
\cline { 2 - 7 } & $\begin{array}{c}\text { Functional } \\
\text { factor }\end{array}$ & $\begin{array}{c}\text { Cosmetic } \\
\text { factor }\end{array}$ & $\begin{array}{c}\text { Overall } \\
\text { result }\end{array}$ & $\begin{array}{c}\text { Functional } \\
\text { factor }\end{array}$ & $\begin{array}{c}\text { Cosmetic } \\
\text { factor }\end{array}$ & Overall result \\
\hline Excellent & 15 & 12 & 12 & 18 & 14 & 14 \\
\hline Good & 10 & 8 & 8 & 5 & 7 & 7 \\
\hline Fair & 1 & 4 & 4 & 1 & 6 & 3 \\
\hline Poor & 1 & 3 & 3 & 6 & 6 \\
\hline
\end{tabular}

Chi- square $\mathrm{p}$ value for functional factor is 0.1468

Chi- square $\mathrm{p}$ value for cosmetic factor is 0.7509

Table 7: Flynn's overall results compared with other series

\begin{tabular}{|c|c|c|c|c|c|c|}
\hline \multirow{2}{*}{ Treatment } & \multirow{2}{*}{ Authors } & \multirow{2}{*}{$\begin{array}{l}\text { No. of } \\
\text { cases }\end{array}$} & \multicolumn{4}{|c|}{ Flynn's overall results (\%) } \\
\hline & & & \multicolumn{4}{|c|}{ Excellent Good Fair Poor } \\
\hline \multirow{3}{*}{ Closed reduction and cast } & Pirone et al ${ }^{15}$ & 101 & 51 & 27 & 3 & 20 \\
\hline & Hadlow et $\mathrm{al}^{18}$ & 55 & 55 & 26 & 4 & 16 \\
\hline & Present study & 22 & 32 & 36 & 18 & 14 \\
\hline \multirow{6}{*}{$\begin{array}{l}\text { Closed reduction and } \\
\text { percutaneous crossed Kirschner } \\
\text { wire pinning }\end{array}$} & Pirone et al ${ }^{15}$ & 96 & 78 & 6 & 1 & 5 \\
\hline & Yadav et $\mathrm{al}^{20}$ & 197 & 74 & 21 & 2 & 3 \\
\hline & Mehserle et $\mathrm{al}^{21}$ & 33 & 7 & 21 & 3 & 6 \\
\hline & Flynn et al ${ }^{9}$ & 52 & 81 & 14 & 4 & 2 \\
\hline & Sutton et al ${ }^{19}$ & 32 & 66 & 22 & 2 & 1 \\
\hline & Present study & 24 & 58 & 29 & 13 & - \\
\hline
\end{tabular}

Table 8. Clinical outcome compared with other series

\begin{tabular}{|l|l|c|c|c|c|}
\hline \multirow{2}{*}{ Treatment } & \multirow{2}{*}{ Authors } & \multirow{2}{*}{$\begin{array}{c}\text { No. of } \\
\text { cases }\end{array}$} & \multicolumn{2}{|c|}{ Movement } & \multirow{2}{*}{ Carrying Angle } \\
\cline { 4 - 6 } & & 101 & $-10.2 \pm 7.6^{\circ}$ & $137 \pm 7.3^{\circ}$ & $6.2 \pm 6.1^{\circ}$ \\
\hline \multirow{2}{*}{ Closed reduction and cast } & Pirone et al ${ }^{15}$ & 22 & $-1.5 \pm 3^{\circ}$ & $131 \pm 7.4$ & $2.2 \pm 5.8^{\circ}$ \\
\cline { 2 - 6 } & Present study & 96 & $-11.2 \pm 6.2^{\circ}$ & $139 \pm 5.1^{\circ}$ & $7.8 \pm 4.6$ \\
\hline \multirow{2}{*}{$\begin{array}{l}\text { Closed reduction and } \\
\text { percutaneous crossed } \\
\text { Kirschner wire pinning }\end{array}$} & Pirone et al & & - & - & $10.2^{\circ}$ \\
\cline { 2 - 6 } & Yadav et al ${ }^{20}$ & 197 & $-1.7 \pm 2.8^{\circ}$ & $132.4 \pm 5.4^{\circ}$ & $5.3 \pm 5^{\circ}$ \\
\cline { 2 - 6 } & Present study & 24 & & & \\
\hline
\end{tabular}

${ }^{\dagger}$ Negative value for extension indicates recurvatum 


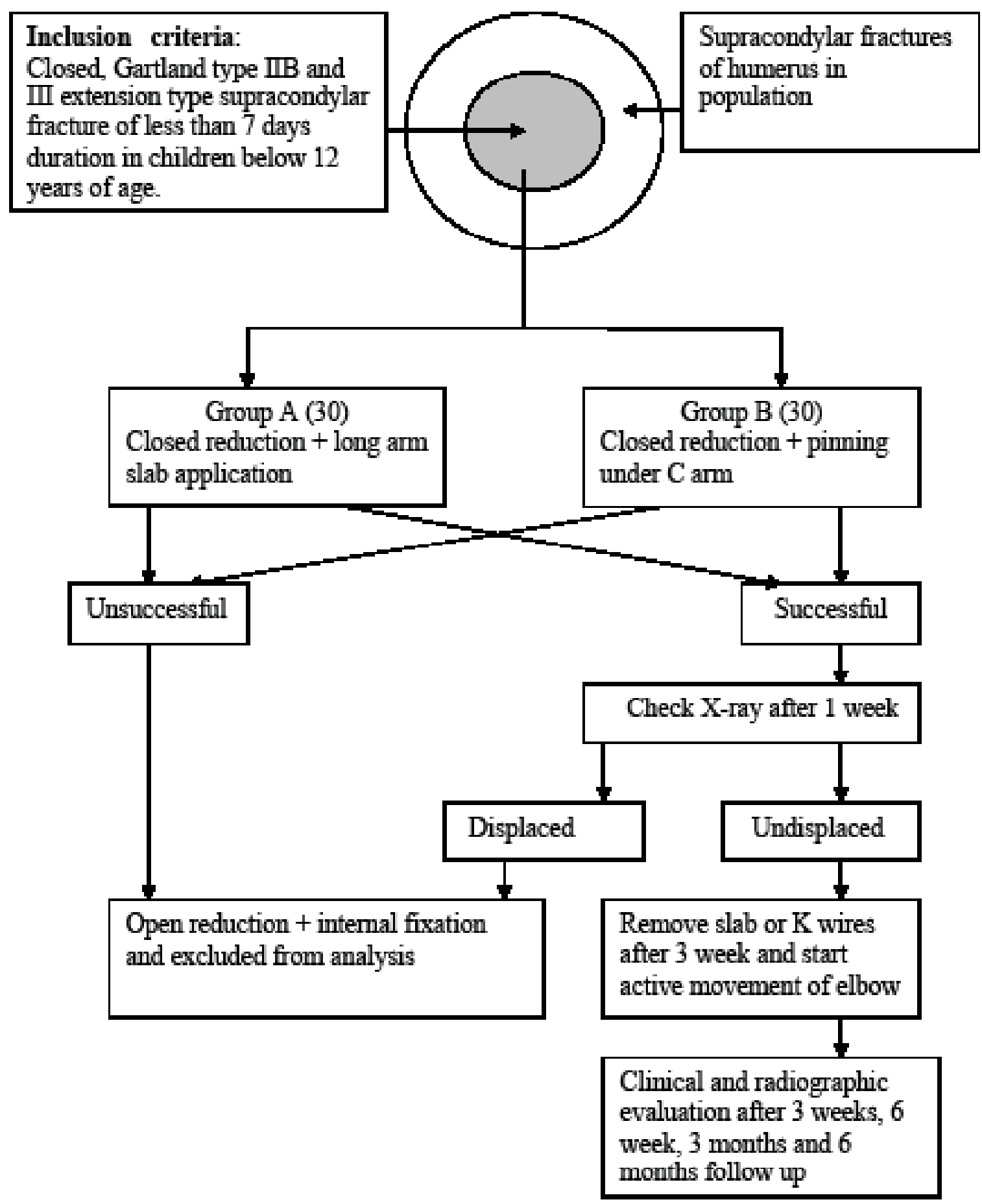

Fig 1: Flow chart showing randomization and allocation of cases into Group A and B 


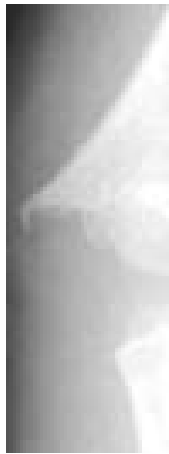

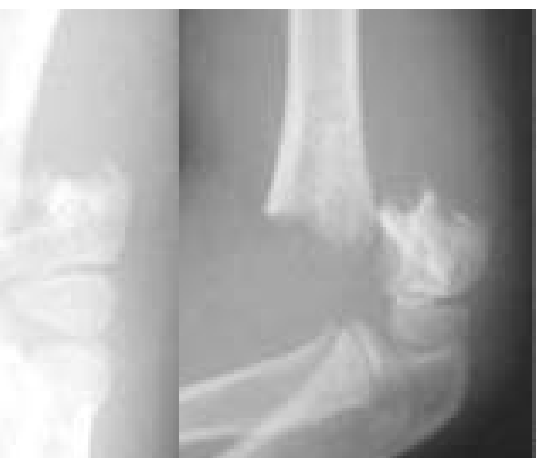

(a)

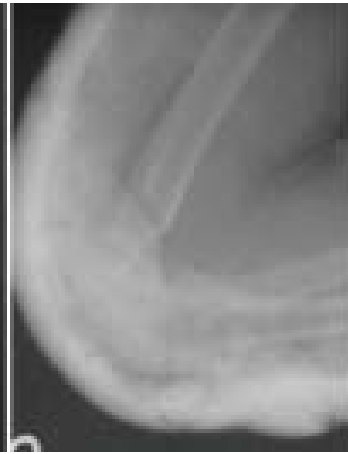

(b)

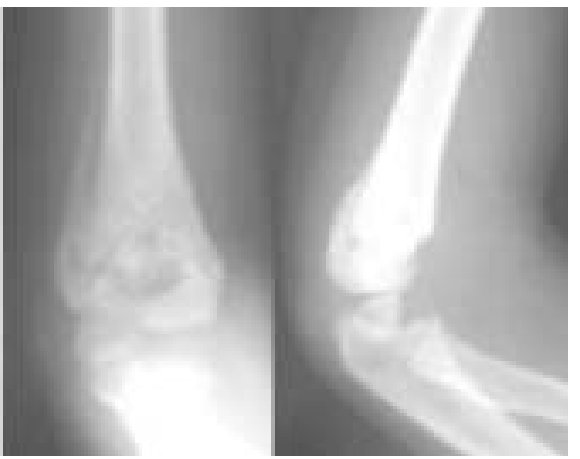

(c)

Fig 2: Gartland type III fracture (a), closed reduction and posterior long arm slab application (b), uniting fracture after 3 weeks (c)

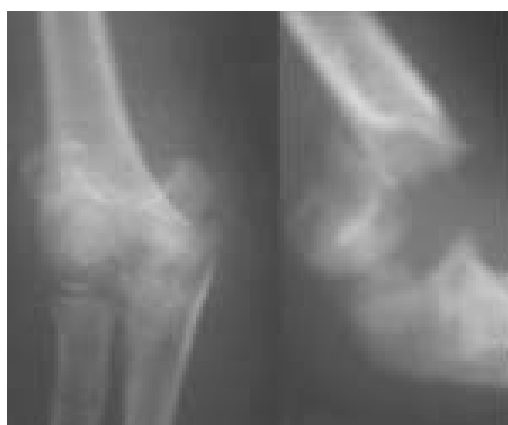

(a)

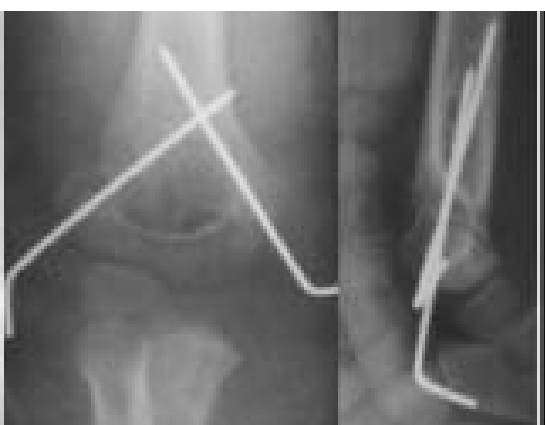

(b)

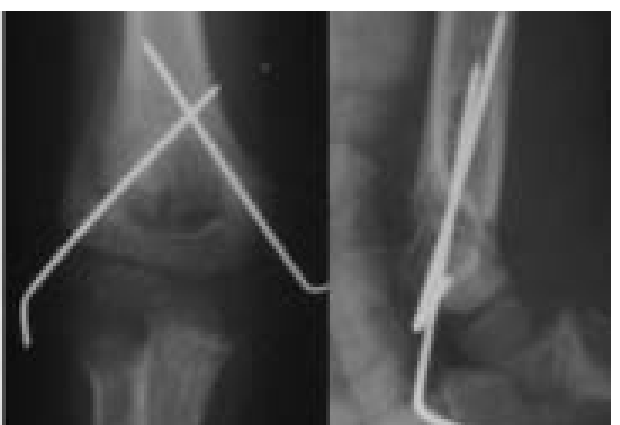

(c)

Fig 3: Gartland type III fracture (a), closed reduction and crossed Kirschner wires fixation (b), uniting fracture after 3 weeks (c)

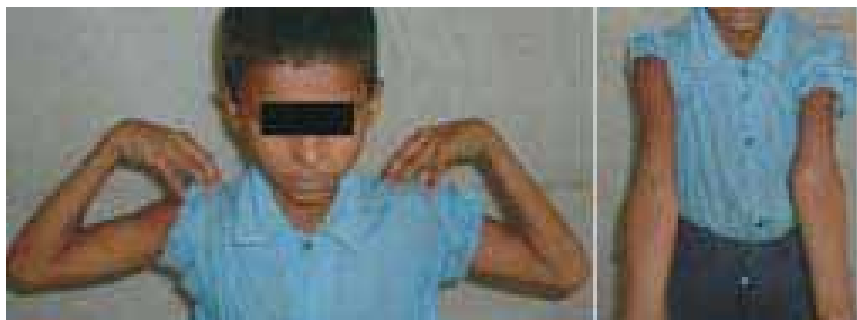

(a)

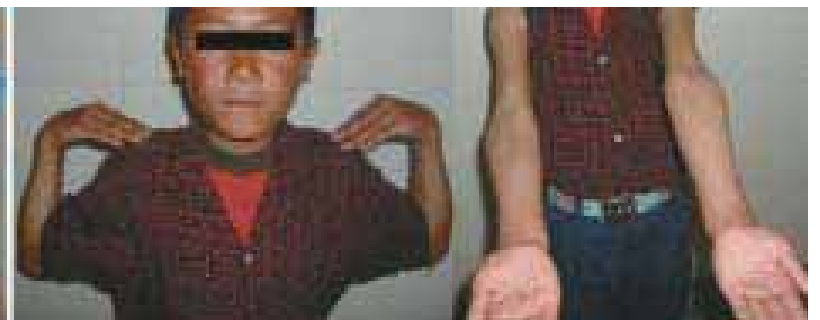

(b)

Fig. 4: Functional and cosmetic results in group A (a) and Group B (b)

\section{Discussion}

Treatment of displaced extension type supracondylar fracture (Gartland type IIB and III) in children is still controversial. Closed reduction and long arm elbow cast or slab in hyperflexed elbow for stability of fracture reduction is the standard method of treatment. But many problems are associated with this method of treatment for displaced supracondylar fracture in children. Acute flexion of elbow produce further vascular compromise in already swollen elbow and increases chances of Volkmann ischaemia where as anything less than acute flexion risks loss of reduction. This problem so called supracondylar dilemma is unique to treatment with closed reduction and cast immobilization ${ }^{14}$. Incidence of cubitus varus deformity is reported up to $14 \%$ with this method because when swelling subsides in situ elbow can extend inside the cast or slab and reduction is $\operatorname{lost}^{1,15}$. In this study, two attempts of closed reduction failed in two cases and one patient failed to retain reduction on first week follow up. Though various methods have been described to control distal fragment, there are many factors over which surgeons have no control ${ }^{15}$. Another problem with this method is accurate assessment of 
Bauman's angle which needs full extension of elbow. ${ }^{4}$ Medial or lateral tilt or shift observed in immediate post reduction Jone's view may be altered because of faulty radiographic techniques. ${ }^{15}$ Present study found $32 \%$ of varus deformity in patients treated with closed reduction and long arm slab application as compare to $12.5 \%$ in patients treated with closed reduction and percutaneous crossed Kirschner wire fixation.

Closed reduction and cross K wire fixation, first described by Swenson in 1948 is accepted method of treatment for displaced extension type supracondylar fracture ${ }^{16}$. Several advantages have been reported of this method of treatment. It provides anatomical reduction, stable fixation and lower incidence of Volkmann Ischaemia as elbow can be immobilized in $\leq 90$ degree of flexion without vascular compromise.

Ong TG et al found percutaneous pinning has the most consistent outcome in 77 patients of supracondylar fractures of humerus in terms of restoration of function and cosmesis when compared with other two methods of treatment; closed reduction and slab application and open reduction and internal fixation ${ }^{17}$. Present study revealed comparable restoration of range of movement of affected elbow in the both methods of treatment. The small reduction of flexion of injured elbow can be attributed to shorter period of follow up period.

Table 7 shows comparison of outcomes according to Flynn's global classification. Results of treatment with closed reduction and fixation with crossed Kirschner wires are comparable but treatment with application of long arm slab has produced inferior result in present study as compared to other studies. Mean values of flexion and extension of elbow and carrying angle of present study with other studies are compared in Table 8.

Some complications are associated with crossed Kirschner wire fixation. Iatrogenic ulnar nerve injury due to medial pin insertion is reported with varying incidence of $2 \%$ to $8 \%{ }^{11}$. Pirone found no case of ulnar nerve injury in 96 cases of percutaneous Kirschner wires fixation ${ }^{15}$. Yadav et al in study of 197 cases have found 3\% of ulnar nerve injury and all recovered in 3-6 weeks with conservative treatment ${ }^{20}$. Boyd and Aronson have reported ulnar nerve injury in $3 \%$ out of 71 cases of supracondylar fractures treated with percutaneous pinning ${ }^{13}$. David et al have shown that prevalence of ulnar nerve injury is $7.7 \%$ in total of 220 patients of supracondylar fractures of humerus treated with closed cross percutaneous pinning ${ }^{22}$. There was one case $(3.3 \%)$ of ulnar nerve injury in present study due to medial pin insertion which resolved completely at 6 weeks. Most patients with ulnar nerve palsy recover spontaneously with conservative method after removal of medial pin ${ }^{1}$. Various methods are described to prevent iatrogenic ulnar nerve injury. The method we adopted is rolling of ulnar nerve posteriorly with opposite thumb while inserting medial pin through medial epicondyle. Other method suggested are passing two lateral pins in flexion of elbow and medial pin in extension ${ }^{1}$; cross wiring entirely from lateral side (Dorgan's technique) ${ }^{11}$; intraoperative electrical stimulation for localizing the nerve ${ }^{23}$. Some authors recommend only two parallel lateral pins if reduction is stable. In spite of various modifications, crossed medial and lateral pins have been found to be most stable configuration biomechanically ${ }^{1,10}$. Errors to be avoided during crossed Kirschner wire fixation are not to place pins too close to fracture site or to allow pins to exit through fracture site. Anatomic reduction and engaging of two cortices by pins are essential ${ }^{2}$.

Pin tract infection is another complication. Pirone has quoted development of superficial pin site infection in 2 cases out of 96 managed with percutaneous Kirschner wires fixation. ${ }^{15}$ Yadav et al have quoted 52 out of 197 patients with mild pin site infection which healed without complications ${ }^{20}$. We did not find pin site infection in our study.

\section{Conclusion}

Functional and cosmetic outcome and preservation of range of movement are better in patients treated with closed reduction and crossed Kirschner wire fixation for displaced supra condylar fracture, however they are either statistically insignificant or small in amount if it is significant which may be attributed to shorter period of follow up. The future study should be conducted with longer follow up, large number of patients and with comparison of various other methods of treatments.

\section{References}

1. Herring JA, editor. Fracture about the elbow. In: Tachdjian's Pediatric Orthopaedics. 3rd ed. Vol. 3. Philadelphia: W.B. Saunders; 2002. 2139221.

2. Sponsellar PD, editor. Injuries of Arm and Elbow. In: Orthopaedic Knowledge Updates Pediatrics. 1st ed. Rosemont: American Academy of Orthopaedic Surgeons; 2002.93107.

3. Gartland JJ. Management of supracondylar fractures of the humerus in children. Surg Gynecol Obstet. 1959;109-54.

4. Wilkins KE: Supracondylar Fracture of the Distal Humerus. In: Rockwood CA, Wilkins KE, Beaty JH. (editors) Fractures in Children. $4^{\text {th }}$ ed. Vol. 3. Philadelphia, Lippincott - Raven; 1996. 669-752. 
5. Dogde HS. Displaced Supracondylar Fractures of Humerus in Children: Treatment by Dunlop's Traction. J Bone Joint Surg [Am]. 1972;54A:1408-18.

6. Dunlop J. Transcondylar Fractures of the Humerus in Childhood. J Bone Joint Surg. 1939;21:59-73.

7. Worlock PH, Chhistopher C. Severely Displaced Supracondylar Fractures of Humerus in Children: A Simple Method of Treatment. J Pediatr Orthop. 1987;7:49-53.

8. Smith FM. Kirschner's Wire Traction in Elbow and Upper Arm Injuries. Am J Surg. 1947;74A:700-87.

9. Flynn JC, Matthews JG, Benoit RC. Blind pinning of displaced Supracondylar Fractures of Humerus in Children- sixteen years' experience with long term follow-up. J Bone Joint Surg [Am]. 1974;56-A:263-272.

10. Mazda K, Boggione C,Fittoussi F,Pemecot GF. Systemic pinning of displaced extension type supracondylar fractures of the humerus in children. J Bone Joint Surg [Br]. 2001;83B:888-93.

11. Shannon FJ, Mohan P."Dorgan's" Percutaneous lateral cross-wiring of supracondylar fractures of humerus in children. J Pediatr Orthop. 2004;24:376-9.

12. Archibald DA, Roberts JA, Smith MG. Transarticular fixation for displaced Supracondylar fractures of humerus in children. J Bone Joint Surg [Br]. 1991;73-B:888-93.

13. Boyd DW, Aronson DD. Supracondylar fractures of the humerus: A prospective study of percutaneous pinning. J Pediatr Orthop. 1992;789-94.

14. Green NE. Fracture and Dislocation about the Elbow. In: Green NE, Swiontkowski MF (editors). Skeletal Trauma In Children. 2nd ed. Vol .3. Philadelphia: W.B. Saunders;1998.259317.
15. Pirone AM, Grahan HK, Krajbich JI. Management of displaced extension-type supracondylar fractures of the humerus in children. J Bone Joint Surg [Am]. 1988;70A:641-50.

16. Swenson AL. The Treatment of Supracondylar Fractures of the Humerus by Kirschner's Wire Traction. J Bone Joint Surg [Am]. 1948;30A:994-7.

17. Ong TG, Low BY. Supracondylar humeral facture a review of the outcome of treatment. Singapore Med J. 1996;37(5):508-11.

18. Hadlow AT, Devane WB, Nicol RO. A selective treatment approach to supracondylar fractures of the humerus in children. . J Paediatr Orthop. 1996;16: 104-6.

19. Sutton WR, Greene WB, Georgepoulos G, Dameron TB Jr. Displaced supracondylar fractures of the humerus in children: a comparison of results and costs in patients treated by skeletal traction versus percutaneous pinning. Clin Orthop. 1992;278:81-7.

20. Yadav UB, Singhal R, Tonk G, Aggrawal T, Verma AN. Crossed pin fixation in displaced supracondylar humerus fractures in children. Indian J Orthopaedics. 2004;38(3):166-9.

21. Mehserle WL, Meehan PL. treatment of the displaced supracondylar fractures of the humerus (type III) with closed reduction and percutaneous cross-pin fixation. J Pediatr Orthop. 1991;11:705-11.

22. SkaggsDL, Hale JM, Basset J, Kaminsky C, Robert MK, Tolo VT. Operative Treatment of Supracondylar Fractures of the humerus in Children. J Bone Joint Surg [Am]. 2001;83-A: 735-40.

23. Wind WM, Schwend RM, Armstrong DG. Predicting ulnar nerve location in pinning of supracondylar humerus fractures. J Pediatr Orthop. 2002;22(4):444-7. 